Вестник НПУА. “Химические и природоохранные технологии”. 2021, №1

УДК 666.942

DOI: 10.53297/18293379-2021.1-18

\title{
ТЕПЛОИЗОЛЯЦИОННЫЙ МАТЕРИАЛ НА ОСНОВЕ ОСТАТКОВ ПИРОЛИЗА УГЛЯ И ОТХОДОВ СТЕКЛА
}

\author{
М.В. Абрамян, Б.В. Мовсисян, Р.А. Аветян, Г.О. Торосян
}

Национальный политехнический университет Армении

\begin{abstract}
В последние десятилетия большой интерес представляют материалы с высоким тепловым сопротивлением, огнеупорные, нетоксичные, с высокими механическими характеристиками, доступные по цене, удобоукладываемые, теплоизоляционные и т.д.

Срок службы имеющихся на рынке теплоизоляционных материалов, например для нитеобразных ватных изоляторов, составляет порядка $10 \ldots 20$ лет, для пенопластов - 7..10 лет. При горении пенопластов выделяется высокотоксичное вещество фосген. Кроме того, во время работы образуются грибки, а также фосген адгезионно несовместим с цементом. Минеральная вата со временем превращается в пыль, а установка внешних теплоизоляционных материалов в зданиях требует обработки поверхности для защиты от прямого атмосферного воздействия, что влечет за собой дополнительные расходы.

В последнее время большим спросом пользуются теплоизоляционные композиционные стекла и стеклокристаллические материалы, синтезируемые из шлакозольных отходов и горных пород.

Целью исследования является изучение угля и твердых отходов пиролиза угля как сырья для производства пеностекла. В работе современными методами анализа изучены химический, фазовый и минералогический составы угля Магавузского месторождения Республики Арцах и твердых остатков его каталитического пиролиза.

По результатам исследований разработан теплоизоляционный материал, в котором отходы пиролиза также играют роль газообразователя. Выбранный режим термообработки обеспечивает получение в объеме равномерно распределенного высокопористого, теплоизоляционного пеностекла с достаточными механическими свойствами.
\end{abstract}

Ключевые слова: уголь, отходы пиролиза, теплоизоляционное пеностекло, бура.

Введение. В последние годы ситуация в различных отраслях промышленности требует поиска научно обоснованных способов комплексного использования отходов.

Научно-техническую революцию невозможно представить без решения экологических проблем. В связи с этим в силикатной промышленности необходимо более широко использовать техногенные отходы для получения изделий из строительных материалов. Это не только решит экологическую 
задачу, но и создаст безотходные энергосберегающие технологии за счет экономии природного сырья.

Особое место занимает производство строительных материалов с различными компонентами, содержащими стекло, ассортимент которых расширяется день ото дня.

Для этой цели широко используются шлаки цветных металлов, зола и шлаки ТЭЦ.

В Республике Армения ежегодно образуется огромное количество топливных шлаков и золы.

Наиболее эффективным способом использования промышленных отходов является производство ситаллов теплоизоляционного стекла, имеющих состав стеклокомпозитов, позволяющий получать дешевые строительные материалы с необходимыми свойствами, размерами и структурой. Кроме того, использование отходов является перспективным направлением в синтезе теплоизоляционных материалов [1].

Постановка задачи. Целью настоящей работы является исследование химического состава угля Магавузского месторождения Республики Арцах, а также твердых остатков его каталитического пиролиза для применения их в силикатной промышленности [2].

Методы и результаты исследования. Исследованы химический состав угля Магавузского месторождения Республики Арцах, а также твердые отходы его каталитического пиролиза. Химический анализ сырья и продуктов пиролиза проводился в соответствии с действующими стандартами: ГОСТ 32212013.

Были исследованы два образца угля Магавузского месторождения (условные N 2 и N 3).

Результаты анализа показывают, что образцы имеют высокое содержание кремнезема, а потери при прокаливании и влагосодержание составляют более половины массы образца (табл. 1).

Таблица 1

Химический состав угля

\begin{tabular}{c|c|c|c|c}
\hline Образец & $\mathrm{SiO}_{2}$ & $\mathrm{Al}_{2} \mathrm{O}_{3}$ & $\mathrm{Fe}_{2} \mathrm{O}_{3}$ & ППП + влага \\
\hline $\mathrm{N} 2$ & 20,0 & 10,0 & 2,2 & 66,4 \\
$\mathrm{~N} 3$ & 35,8 & 7,2 & 2,1 & 54,6 \\
\hline
\end{tabular}

Рентгенофазовым анализом (РФА) установлено, что $\mathrm{SiO}_{2}$ в обоих образцах представлен в виде кварца. Результаты исследования представлены на рис. 1. 


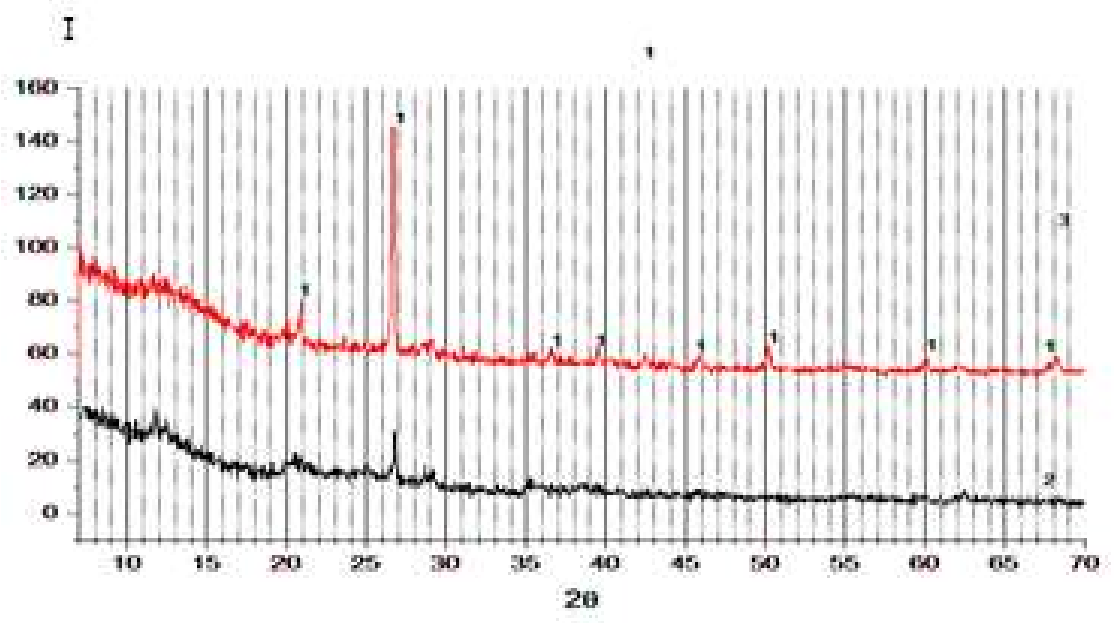

Рис.1. Результаты рентгенофазового анализа образцов угля N2 и N3

Для выяснения изменений, происходящих с материалом в процессе нагревания, исследуемые образцы были подвергнуты дифференциальнотермическому (ДТА) и термовесовому анализам (рис. 2). Исследование проводилось на анализаторе венгерского производства при температуре до $1000^{\circ} \mathrm{C}$ и скорости нагрева $10^{\circ} \mathrm{C} /$ мин, инертный материал эталон- $\mathrm{Al}_{2} \mathrm{O}_{3}$, обжигаемый при температуре $1200^{\circ} C$.

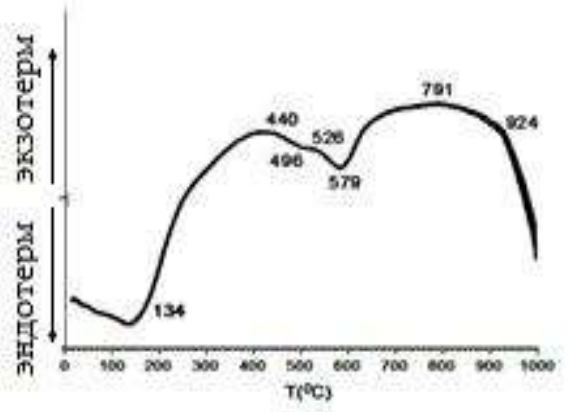

a)

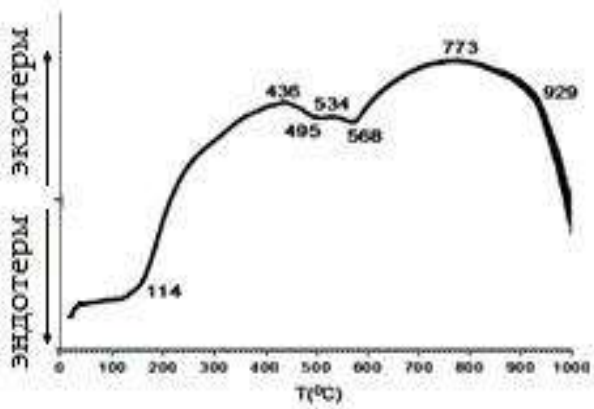

б)

Рис. 2. Сравнительные кривые ДТА образиов угля N3 (а) и N2 (б)

Сравнительный анализ кривых ДТА показывает, что эти кривые практически не различаются по природе, с небольшими отклонениями температуры, вероятно, из-за содержания примесей, образующих твердые растворы. Термический анализ подтверждает содержание кварца в угольных образцах. Экзотермические пики на кривых нагрева при $114^{\circ} \mathrm{C}$ (образец N3) и 
$134^{\circ} \mathrm{C}$ (образец N2), вероятно, связаны с модификационным превращением кварца:

$$
\begin{gathered}
\gamma \text { тридимит } \leftrightarrow \beta \text { тридимит } \\
117^{\circ} \mathrm{C}
\end{gathered}
$$

Эндотермические эффекты при $579^{\circ} \mathrm{C}$ (образец N3) и $568^{\circ} \mathrm{C}$ (образец $\mathrm{N} 2$ ), вероятно, связаны с полиморфным превращением:

$$
\beta \text {-кварц } \leftrightarrow \alpha \text {-кварц }
$$

$573^{\circ} \mathrm{C}$

Исследования угольных образцов Магавузского месторождения показывают, что содержание неорганических компонентов довольно высокое, поэтому продукты их каталитического пиролиза могут быть использованы в качестве сырья в производстве силикатных материалов.

Были изучены также твердые остатки каталитического пиролиза угля Магавузского месторождения. По результатам химического анализа отходы имеют следующий химический состав (в масс.\%) (табл. 2).

Таблица 2

Химический состав твердых остатков пиролиза

\begin{tabular}{c|c|c|c|c|c|c|c|c}
\hline Образец & $\mathrm{SiO}_{2}$ & $\mathrm{Al}_{2} \mathrm{O}_{3}$ & $\mathrm{Fe}_{2} \mathrm{O}_{3}$ & $\mathrm{CaO}$ & $\mathrm{MgO}$ & $\mathrm{Na}_{2} \mathrm{O}_{3} \div \mathrm{K}_{2} \mathrm{O}$ & $\begin{array}{c}\text { Другие } \\
\text { соединения }\end{array}$ & ППП + влага \\
\hline 1 & 34,5 & 11,0 & 4,4 & 0,5 & 0,031 & - & 6,5 & 42,44 \\
3 & 28,68 & 10,7 & 5,071 & 0,672 & 0,047 & 0,497 & 13,83 & 40,5 \\
\hline
\end{tabular}

РФА установлено, что $\mathrm{SiO}_{2}$ как основная составляющая отходов в обоих образцах представлен в виде кварца.

ДТА и термовесовыми методами анализа были выявлены изменения в процессе термической обработки твердых остатков каталитического пиролиза угля (рис. 3).

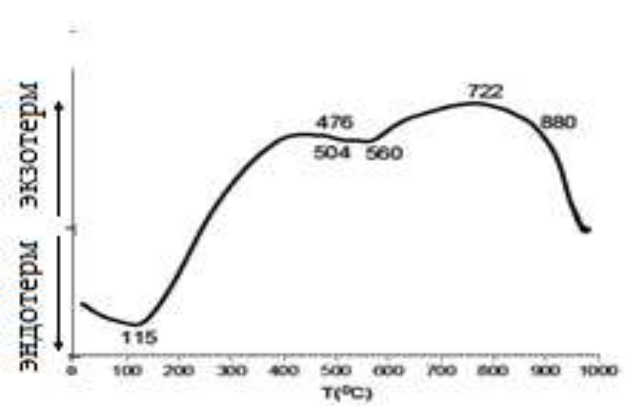

Рис. 3. Кривые ДТА твердых остатков пиролиза угля

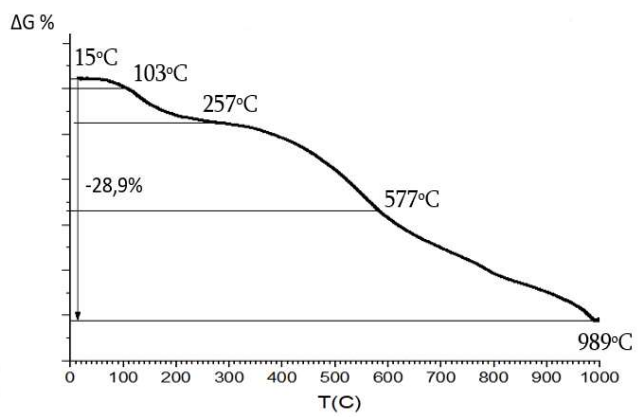

Рис. 4. Кривая потери массы остатков пиролиза угля 
Как видно, на кривой ДТА нет существенных изменений по сравнению с термограммами исходных образцов углерода. Небольшие температурные отклонения связаны с изменением соотношения составляющих в смеси (рис. 3).

Исследования показывают, что отходы характеризуются относительно высоким содержанием оксидов кремния, алюминия и железа, а также высокими потерями при прокаливании. Результаты ДТА и термовесового анализа показывают, что интенсивное газообразование происходит в интервале температур $600 \ldots 800^{\circ} \mathrm{C}$ (рис. 4).

Разработан состав пеностекла. В качестве компонентов пеностекла использовались стеклобой, отходы пиролиза угля, которые также действуют как газообразующий агент, а также тетраборат натрия как флюсообразующий (табл.3) [3-6].

Таблица 3

Состав пеностекла

\begin{tabular}{c|c|c|c}
\hline Образец & \multicolumn{3}{|c}{ Массовое содержание компонентов, \% } \\
\hline & Стеклобой & Отходы пиролиза & $\begin{array}{c}\text { Тетраборат натрия } \\
\mathrm{Na}_{2} \mathrm{~B}_{4} \mathrm{O}_{7}\end{array}$ \\
\hline 1 & 90 & 10 & 5 \\
2 & 80 & 20 & 5 \\
3 & 70 & 30 & 5 \\
4 & 60 & 40 & 5 \\
5 & 50 & 50 & 5 \\
6 & 40 & 60 & 5 \\
7 & 30 & 70 & 5 \\
8 & 20 & 80 & 5 \\
9 & 10 & 90 & 5 \\
\hline
\end{tabular}

Использовалось стекло, синтезированное на основе горных пород Армении (перлита и доломита) как стеклобой, который можно заменить любыми стекольными отходами.

Внешний осмотр полученных пеностекол показал, что составы стекол различаются по объемной пористости.

Составы стекол $\mathrm{N} 2$ и $\mathrm{N} 3$ испытывались с различным количеством буры (табл.4). 
Таблица 4

Состав шихты пеностекла с различным содержанием буры

\begin{tabular}{c|c|c|c}
\hline \multirow{2}{*}{$\mathrm{N}$ п/п } & \multicolumn{3}{|c}{ Массовое содержание компонентов, \% } \\
\cline { 2 - 4 } & Стеклобой & Отходы пиролиза & $\begin{array}{c}\text { Тетраборат натрия } \\
\mathrm{Na}_{2} \mathrm{~B}_{4} \mathrm{O}_{7}\end{array}$ \\
\hline $2-2$ & 80 & 20 & 2 \\
$2-4$ & 80 & 20 & 4 \\
$2-5$ & 80 & 20 & 5 \\
$2-7$ & 80 & 20 & 7 \\
$3-2$ & 70 & 30 & 2 \\
$3-4$ & 70 & 30 & 4 \\
$3-5$ & 70 & 30 & 5 \\
$3-7$ & 70 & 30 & 7 \\
\hline
\end{tabular}

Внешний осмотр стекла показал, что стекла 2-2; 3-2 с содержанием буры до $4 \%$ отличаются большей плотностью в широком сечении практически без пор. Стекла с содержанием буры $5 . .7 \%$ выделялись легким весом, равномерно распределенными порами в объеме стекла.

Изучены основные технологические свойства полученного пористого стекла: плотность, пористость и показатели прочности (табл. 5), (рис. 5, 6).

Таблица 5

Физико-химические свойства пеностекла

\begin{tabular}{|c|c|c|c|}
\hline $\begin{array}{c}\mathrm{N} \\
\Pi / \Pi \\
\end{array}$ & $P$, , $/ \mathrm{CM}^{3}$ & $\begin{array}{c}\text { Пористость, П, } \\
\% \\
\end{array}$ & $\begin{array}{c}\text { Прочность при сжатии, } \\
\mathrm{R}_{\text {сжат }}, H / \mathrm{M}^{2} \\
\end{array}$ \\
\hline $2-4$ & 0,5702 & 26,2 & 2,42 \\
\hline $2-5$ & 0,5302 & 33,1 & 2,30 \\
\hline $2-7$ & 0,5152 & 35,3 & 2.21 \\
\hline $3-4$ & 0,4668 & 37,7 & 2,18 \\
\hline $3-5$ & 0,4314 & 45,7 & 1,73 \\
\hline $3-7$ & 0,4054 & 49,8 & 1,13 \\
\hline
\end{tabular}




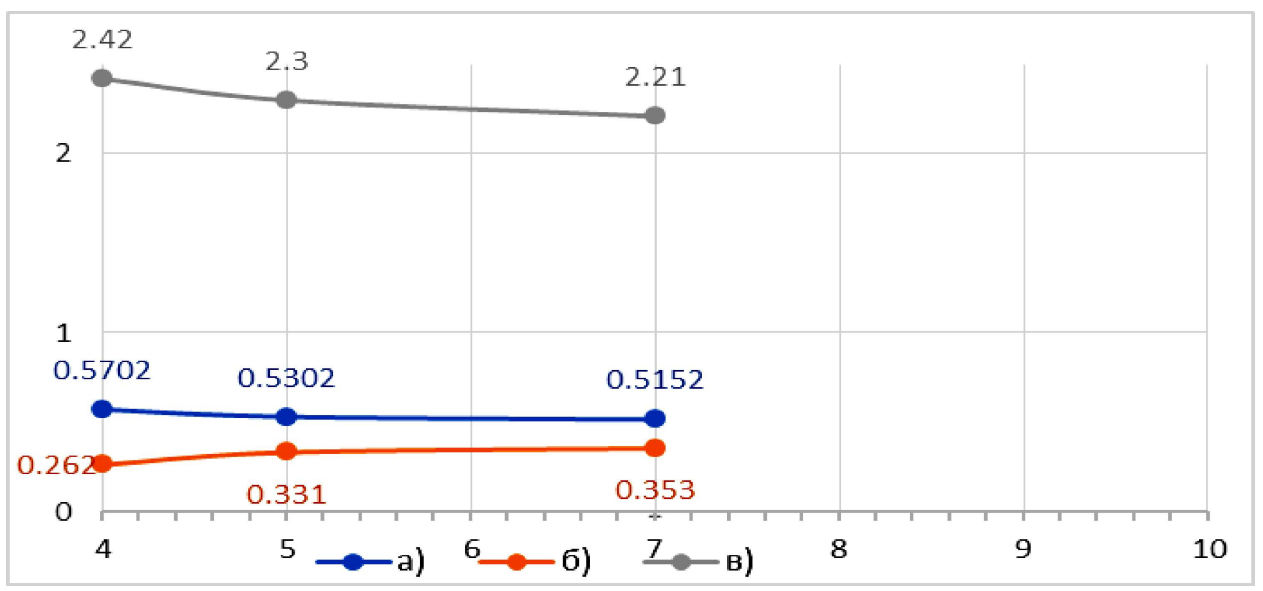

Рис.5. Свойства стекла с различным содержанием буры (2-4, 2-5, 2-7):

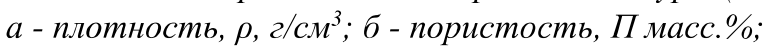

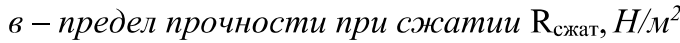

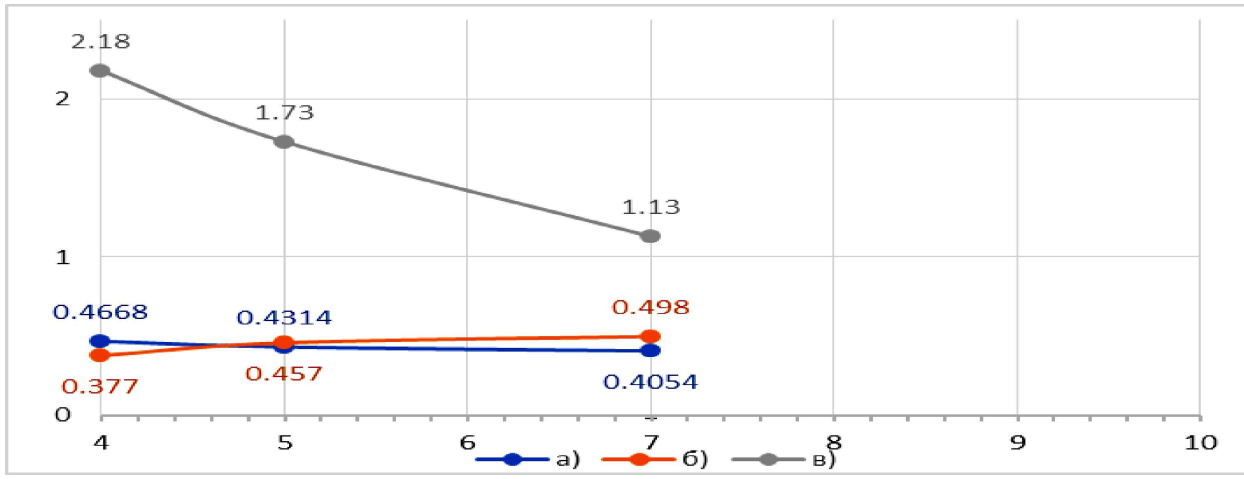

Рис.6. Свойства стекла с различным количеством буры (3-4, 3-5, 3-7):

a - плотность, $\rho$ г/см ${ }^{3}$; б - пористость, Пмасс.\%;

в - предел прочности при сжатии $R_{\text {сжат, } H / M^{2}}$

Как видно из результатов исследования, увеличение количества отходов пиролиза, а также содержания буры приводит к снижению плотности стекла, а также увеличению открытой пористости, но снижению прочности. При сочетании этих показателей оптимальными считаются составы стекол 3-4 и 3-5.

По результатам исследований разработан технологический режим получения пеностекла (рис. 7).

Пеностекло с разработанным составом загружают в холодную печь, где подвергают термообработке со скоростью от $15^{\circ} \mathrm{C} / \mathrm{Muн}$ до $650^{\circ} \mathrm{C}$, 
выдерживают при этой температуре 30 мин, обеспечивая равномерный нагрев, что положительно сказывается на дальнейшем процессе вспенивания. Вспенивание происходит при температуре $900^{\circ} \mathrm{C}$, время хранения при этой температуре - $20 \mathrm{мин.} \mathrm{Чтобы} \mathrm{сохранить} \mathrm{полученную} \mathrm{структуру,} \mathrm{ее} \mathrm{резко}$ охлаждают до $750^{\circ} \mathrm{C}$ в течение 20 минут, затем охлаждают до комнатной температуры со скоростью $2,5^{\circ} \mathrm{C} /$ мин.

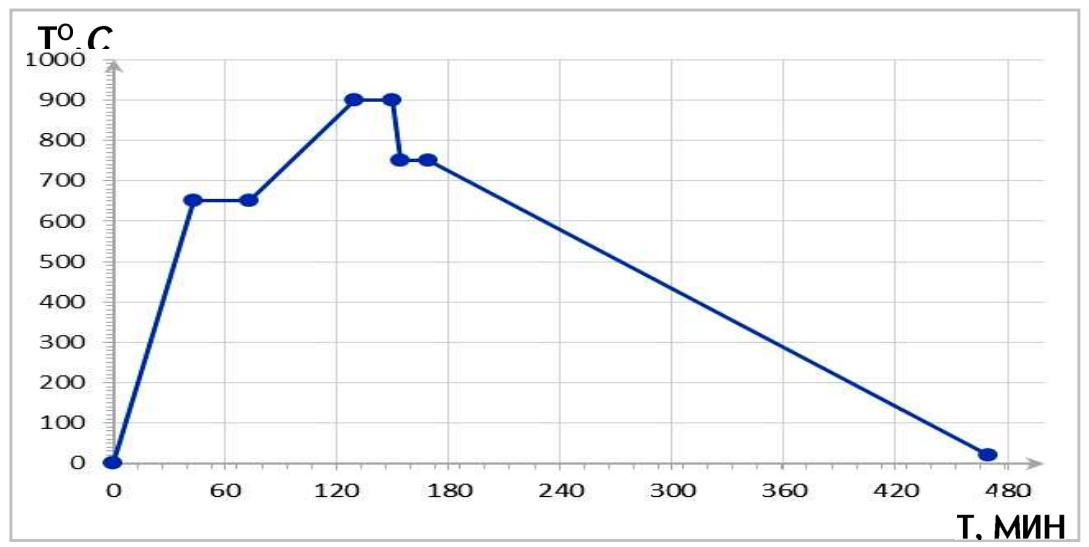

Рис. 7. Режим получения пеностекла

Такой режим термообработки обеспечивает получение теплоизоляционного пеностекла с высокой пористостью, равномерно распределенной в объеме стекла, с достаточными механическими свойствами.

\section{Bblвodbl}

1. Результаты химического, рентгенофазового, дифференциальнотермического и термовесового анализов образцов угля Магавузского месторождения Республики Арцах свидетельствуют о достаточно высоком содержании негорючей части руды.

2. Из результатов анализа следует, что содержание кремнезема в исследуемых образцах составляет $30 . .40$ мас.\%, что дает основание использовать его в качестве кремнеземистого сырья в производстве пеностекла.

3. Результаты дифференциально-термического и термовесового анализов показывают, что потеря массы твердых отходов пиролиза достаточно высока $(40 \ldots 45 \%)$, а интенсивное газообразование происходит в интервале температур $600 \ldots 800^{\circ} \mathrm{C}$. 
4. Разработаны составы теплоизоляционного пеностекла с использованием отходов пиролиза, а также технологический режим их получения.

\section{Литература}

1. Казанцева Л.К., Стороженко Г.И. Особые свойства пеностекла из природного сырья // Строительные материалы. -2014. -№ 11.-С. 34-36.

2. Изучение твердых отходов каталитического пиролиза угля Магавузского месторождения Республики Арцах и возможности их применения в производстве цемента/ М.В. Абрамян, Н.Ю. Аракелян, А.А. Аристакесян и др. // Вестник НПУА: Химические и природоохранные технологии. - 2019.N.1.-C. 34-39.

3. Спиридонов Ю.А., Орлова Л.А. Проблемы получения пеностекла// Стекло и керамика. -2003. -№ 10.- С.10-11.

4. Пеностекло. Научные основы и технология / Н.И. Минько и др. Воронеж: Науч. книга, 2008. -168 с.

5. Верещагин В.И., Соколова С.Н. Гранулированный пеностеклокристаллический теплоизоляционный материал из цеолитсодержащих пород// Строительные материалы. -2007. -№ 3. -С. 66-67.

6. Fernandes H.R., Tulyaganov D.U., Ferreira J.M.F. Preparation and characterization of foams from sheet glass and fly ash using carbonates as foaming agents// Ceramics International. -2009. - Vol. 35, No. 1.-P. 229-235.

Поступила в редакиию 30.04.2021. Принята к опубликованию 13.05.2021.

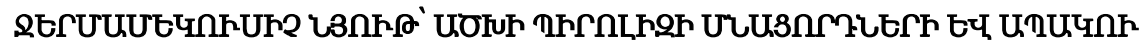

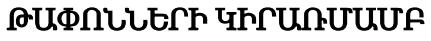

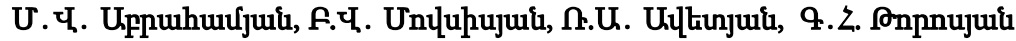

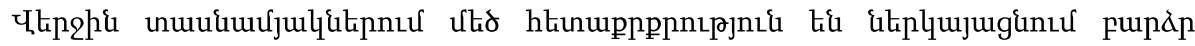

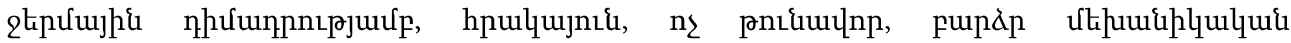

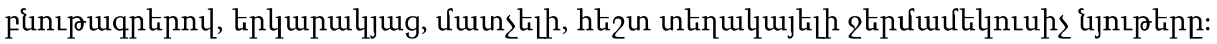

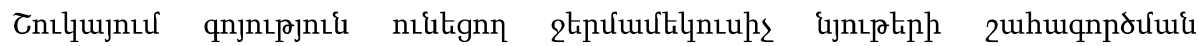

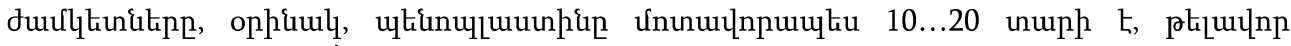

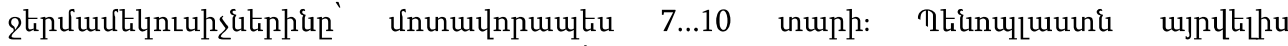

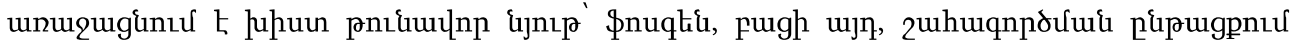

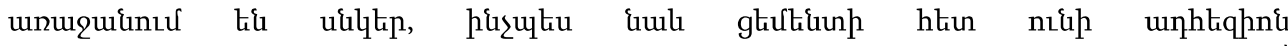

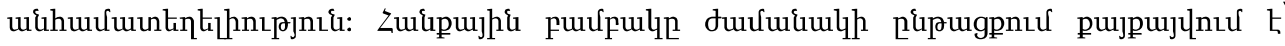

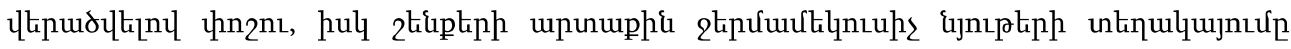




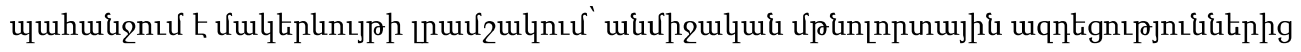

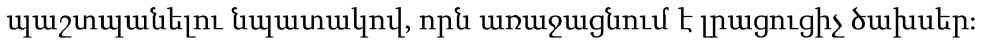

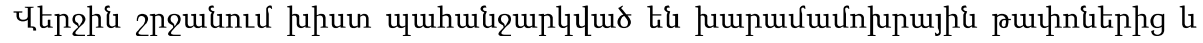

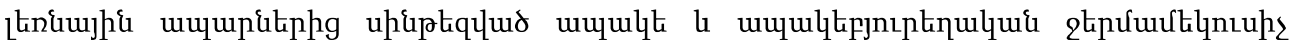
दnưupnqhghni ujnıpten:

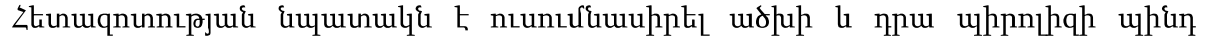

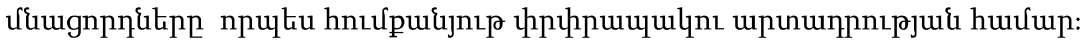

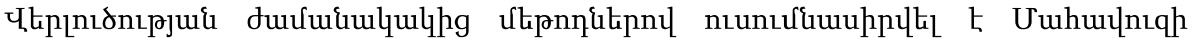

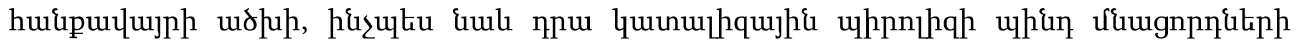

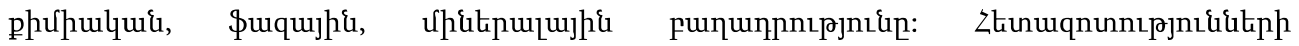

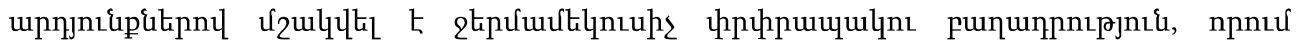

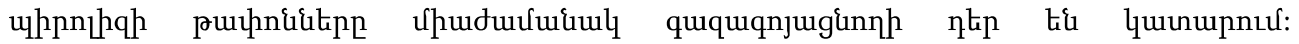

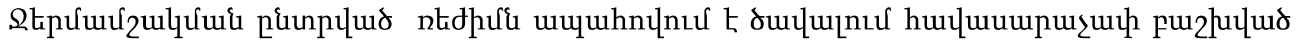

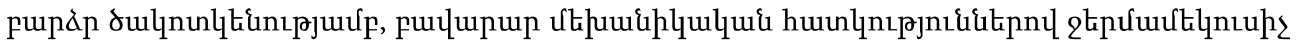

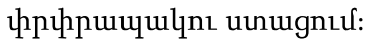

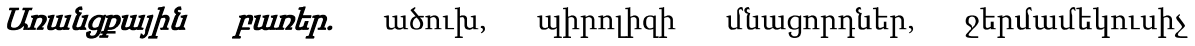
црицрищullh, pnpupu:

\section{A THERMAL INSULATING MATERIAL BASED ON RESIDUES OF PYROLYSIS COAL AND GLASS WASTE}

\section{M.V. Abrahamyan, B.V. Movsisyan, R.A. Avetyan, G.H. Torosyan}

In recent decades, materials with high thermal resistance, refractory, non-toxic, with high mechanical characteristics, durable, affordable easy-to-install thermal insulation materials are of great interest. Durability of available thermal insulating materials, for example cotton insulators is from 10 to 20 years, foam is from 7 to 10 years. During burning process of foam plastics, high-toxic material called phosgene is released.

At the same time, fungus forms during the process, and it has adhesion incompatibility with cement. Mineral wool decomposes over time, turning into powder, and the installation of external thermal insulation materials in buildings requires surface finishing to protect it from direct weathering, which incurs additional costs.

Recently, composite glasses, glass-crystalline materials synthesized from slag-ash wastes of rocks are in great demand.

The goal of this research is to study coal and solid waste of coal pyrolysis as a raw material for the foam glass production.

In this work, the chemical, phase and mineralogical composition of coal from the Magavuz deposit in the Republic of Artsakh and solid residues of its catalytic pyrolysis have been studied by the modern methods of analysis.

Based on the results, a heat-insulating material has been developed, in which pyrolysis waste also plays the role of a gas generator. The selected heat treatment mode ensures the production of heat-insulating foam with high porosity, uniformly distributed in the volume, with sufficient mechanical properties.

Keywords: coal, pyrolysis waste, heat-insulating foam glass, borax. 